\title{
Hydrogen Atom Scrambling in Selectively Labeled Anionic Peptides Upon Collisional Activation by MALDI Tandem Time-of-Flight Mass Spectrometry
}

\author{
Nicolai Bache, ${ }^{\text {a }}$ Kasper D. Rand, ${ }^{\text {a }}$ Peter Roepstorff, ${ }^{\text {a }}$ Michael Ploug, ${ }^{\text {b }}$ and \\ Thomas J. D. Jørgensen ${ }^{\mathrm{a}}$ \\ a Department of Biochemistry and Molecular Biology, University of Southern Denmark, Odense, Denmark \\ ${ }^{b}$ Finsen Laboratory, Rigshospitalet/Copenhagen Biocenter, Copenhagen, Denmark
}

We have previously shown that peptide amide hydrogens undergo extensive intramolecular migration (i.e., complete hydrogen scrambling) upon collisional activation of protonated peptides (Jørgensen et al. J. Am. Chem. Soc. 2005, 127, 2785-2793). The occurrence of hydrogen scrambling enforces severe limitations on the application of gas-phase fragmentation as a convenient method to obtain information about the site-specific deuterium uptake for proteins and peptides in solution. To investigate whether deprotonated peptides exhibit a lower level of scrambling relative to their protonated counterparts, we have now measured the level of hydrogen scrambling in a deprotonated, selectively labeled peptide using MALDI tandem time-of-flight mass spectrometry. Our results conclusively show that hydrogen scrambling is prevalent in the deprotonated peptide upon collisional activation. The amide hydrogens $\left({ }^{1} \mathrm{H} /{ }^{2} \mathrm{H}\right)$ have migrated extensively in the anionic peptide, thereby erasing the original regioselective deuteration pattern obtained in solution. (J Am Soc Mass Spectrom 2008, 19, 1719-1725) (c) 2008 American Society for Mass Spectrometry

$\mathrm{T}$ The fragmentation behavior of protonated peptides upon collisional activation has been the focus of many experimental and theoretical studies [1]. In comparison, deprotonated peptides have received much less attention, and the mechanistic details of their fragmentation behavior are less well understood. We and others have previously investigated the proton mobility in protonated peptides and proteins upon collision-induced dissociation (CID) [2-12]. Our studies were motivated by earlier reports claiming that CID could be used to determine site-specific incorporation of deuterium in the backbone amides of peptides that were deuterated in solution [13-16]. In these reports, it was suggested that the level of intramolecular migration of amide hydrogens $\left({ }^{1} \mathrm{H} /{ }^{2} \mathrm{H}\right)$ in the protonated, collisionally activated peptide was negligible. It is important to emphasize that negligible levels of hydrogen migration would dramatically improve the resolution of localizing deuterated sites by mass spectrometric analysis of peptides and proteins labeled in solution $\left({ }^{1} \mathrm{H} /{ }^{2} \mathrm{H}\right)$ exchange experiments. But recent results have demonstrated unequivocally that all backbone amide hydrogens are positionally randomized upon collisional activation in the gaseous protonated peptide (i.e.,

Address reprint requests to Dr. Thomas J. D. Jørgensen, Department of Biochemistry and Molecular Biology, University of Southern Denmark, Campusvej 55, 5230 Odense M, Denmark. E-mail: tjdj@bmb.sdu.dk causing $100 \%$ hydrogen scrambling) $[3,6,7,10]$. This implies that protonation of amide nitrogens is a reversible process in the gaseous activated peptide, and that the mobile proton (or deuteron) samples all exchangeable sites before peptide bond cleavage. Interestingly, this also occurs in singly protonated peptides exhibiting a preferred site-selective cleavages at Asp residues, which are thought to be induced by a reduced proton mobility [6]. Deprotonated peptides are deficient in protons and it is thus reasonable to assume that such ions might exhibit a lower degree of hydrogen scrambling than their protonated counterparts. Furthermore, low-energy CID of deprotonated peptides often yield a fragment ion type (c-ion) that is observed only rarely in protonated peptides [17]. The c-ion is the N-terminal fragment ion that results from backbone $\mathrm{N}-\mathrm{C}_{\alpha}$ bond cleavage. As anionic peptides thus exhibit different fragmentation pathways (relative to their protonated counterparts) and they have a proton deficit, we have explored the extent of intramolecular migration of amide hydrogens during collisional activation using a unique model peptide with a receptor induced regioselective deuterium labeling [18].

A well-defined deuterium incorporation is the key requirement for an accurate assessment of the level of amide hydrogen scrambling during gas-phase activation. With our unique model peptide, the amides in the $\mathrm{N}$-terminal half are protiated, while the amides in its 
C-terminal half are deuterated as a consequence of a high-affinity interaction with the urokinase receptor $[6,7,18]$. If amide hydrogen scrambling occurs upon gas-phase activation, the deuterons will inevitably migrate towards the $\mathrm{N}$-terminal half, while its amide protons simultaneously migrate to the C-terminal half. This positional randomization is readily detected as a mass increase for the fragment ions of the N-terminal half. The selective labeling of the intact peptide is conveniently accomplished in solution as the C-terminal half harbors the high-affinity urokinase receptor-binding sequence, whereas the N-terminal half comprise a nonbinding sequence that remains solvent exposed in the complex. The receptor-binding sequence of the model peptide adopts an $\alpha$-helical structure when it binds to the hydrophobic ligand-binding cavity of the urokinase receptor (Figure 1) [19]. The intramolecular hydrogen bonds in the $\alpha$-helix protect the backbone amide hydrogens in the C-terminal half against isotopic exchange with the solvent, while the N-terminal half is solvated and thus undergoes rapid isotopic exchange (Figure 2). The selective labeling of the peptide is carried out by diluting fully deuterated peptide-receptor complex into a protiated buffer. After a few seconds, the N-terminal half is protiated, while the C-terminal half remains deuterated due to its tight interaction with the receptor. Upon lowering the $\mathrm{pH}$ and the temperature, the amide hydrogen exchange reaction is quenched and the complex dissociates, thereby liberating a selectively labeled peptide for the following MS/MS experiments.

\section{Experimental}

\section{Materials and Methods}

$\mathrm{D}_{2} \mathrm{O}(99.9$ atom \% D) was obtained from Cambridge Isotope Laboratories (Andover, MA). Ammonium acetate- $\mathrm{d}_{7}$ (98 atom \% D) and the MALDI matrix: $\alpha$-cyano-4hydroxycinnamic acid (HCCA) were from SigmaAldrich (St. Louis, MO). All other chemicals and reagents were of the highest grade commercially available. The AE133 peptide (KGSGGD-Cha-FsrYLWS, Cha is $\beta$-cyclohexylalanine, lower case letters denote D-chirality) was synthesized as reported previously $[20,21]$. Soluble, recombinant human urokinase-type plasminogen activator receptor (uPAR) was produced in CHO-cells and immunoaffinity purified as described previously [22].

\section{Selective Labeling}

Selectively labeled peptides were prepared as described previously [6]. In brief, fully deuterated UPAR-peptide complexes were prepared by mixing a 2-fold molar excess of deuterated uPAR with deuterated peptide. The selective labeling was achieved by a 50-fold dilution of deuterated uPAR-peptide complexes into protiated buffer (i.e., exchange-out): $1 \mu \mathrm{L}$ of a $200 \mu \mathrm{M}$ solution of the peptide ligand in the presence of $400 \mu \mathrm{M}$
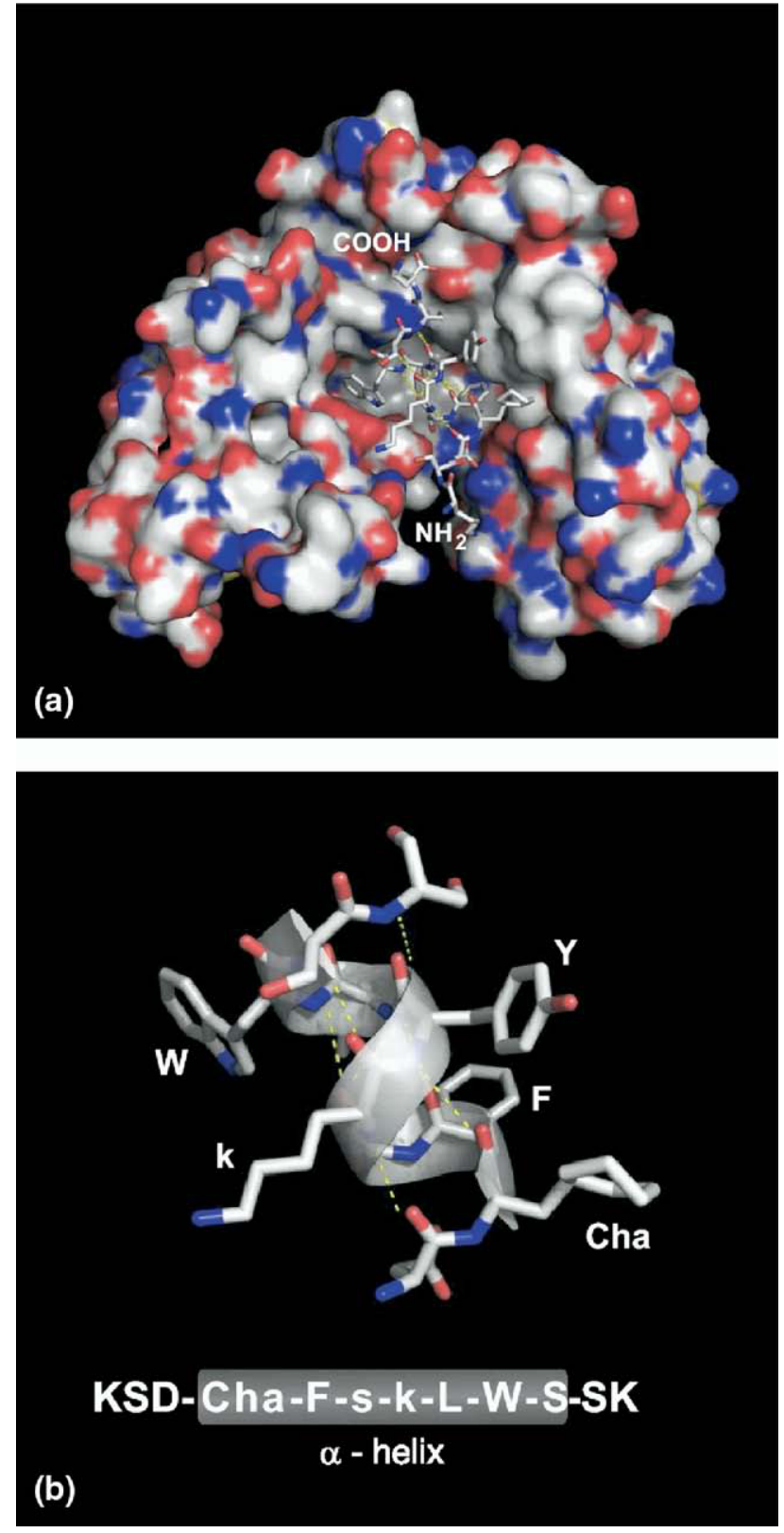

Figure 1. Crystal structure of the model peptide antagonist in complex with UPAR. (a) The crystal structure solved for UPAR in complex with the peptide antagonist AE147 (KSD-ChaFskYLWSSK) is shown using a surface representation for UPAR and a stick representation for AE147. Intramolecular hydrogen bonding of the main chain in AE147 is highlighted by yellow dashes. Note the efficient burial of the peptide in the large hydrophobic ligand-binding cavity in UPAR. (b) The core of the receptor-bound peptide (D-Cha-FskYLWSS) is shown in a close-up as a stick representation superimposed onto a semitransparent ribbon diagram illustrating the right-handed $3.6 \alpha$-helix of AE147 that is stabilized upon binding to UPAR. Color coding according to atoms is white (carbon), blue (nitrogen), red (oxygen), and orange (sulfur). These molecular representations were created by PyMol (DeLano Scientific), using the PDB coordinates 1YWH [19].

uPAR in deuterated buffer (50 $\mathrm{mM} d_{7}$-ammonium acetate, $\mathrm{pH} 8.0,0.10 \mathrm{M} \mathrm{NaCl}$ ) was added to $49 \mu \mathrm{L}$ of the corresponding protiated buffer (i.e., $50 \mathrm{mM}$ ammonium 
acetate buffer, $\mathrm{pH} 8.0,0.10 \mathrm{M} \mathrm{NaCl}$ ). Solutions maintained at $0{ }^{\circ} \mathrm{C}$ were subjected to exchange for $30 \mathrm{~s}$. The ${ }^{1} \mathrm{H} /{ }^{2} \mathrm{H}$ exchange solution was quenched by the addition of an equal volume of $0.5 \mathrm{M}$ phosphate buffer $(\mathrm{pH}$ 2.2, $0^{\circ} \mathrm{C}$ ) and subjected immediately to rapid desalting.

\section{Rapid Desalting and MALDI Sample Preparation}

A chromatographic microcolumn (made in-house) was used to desalt the selectively labeled peptide before mass spectrometric analysis. The microcolumn was prepared using Eppendorf GE Loader pipette tips packed with a reversed-phase material for perfusion chromatography (POROS R2; Applied Biosystems, Fra-

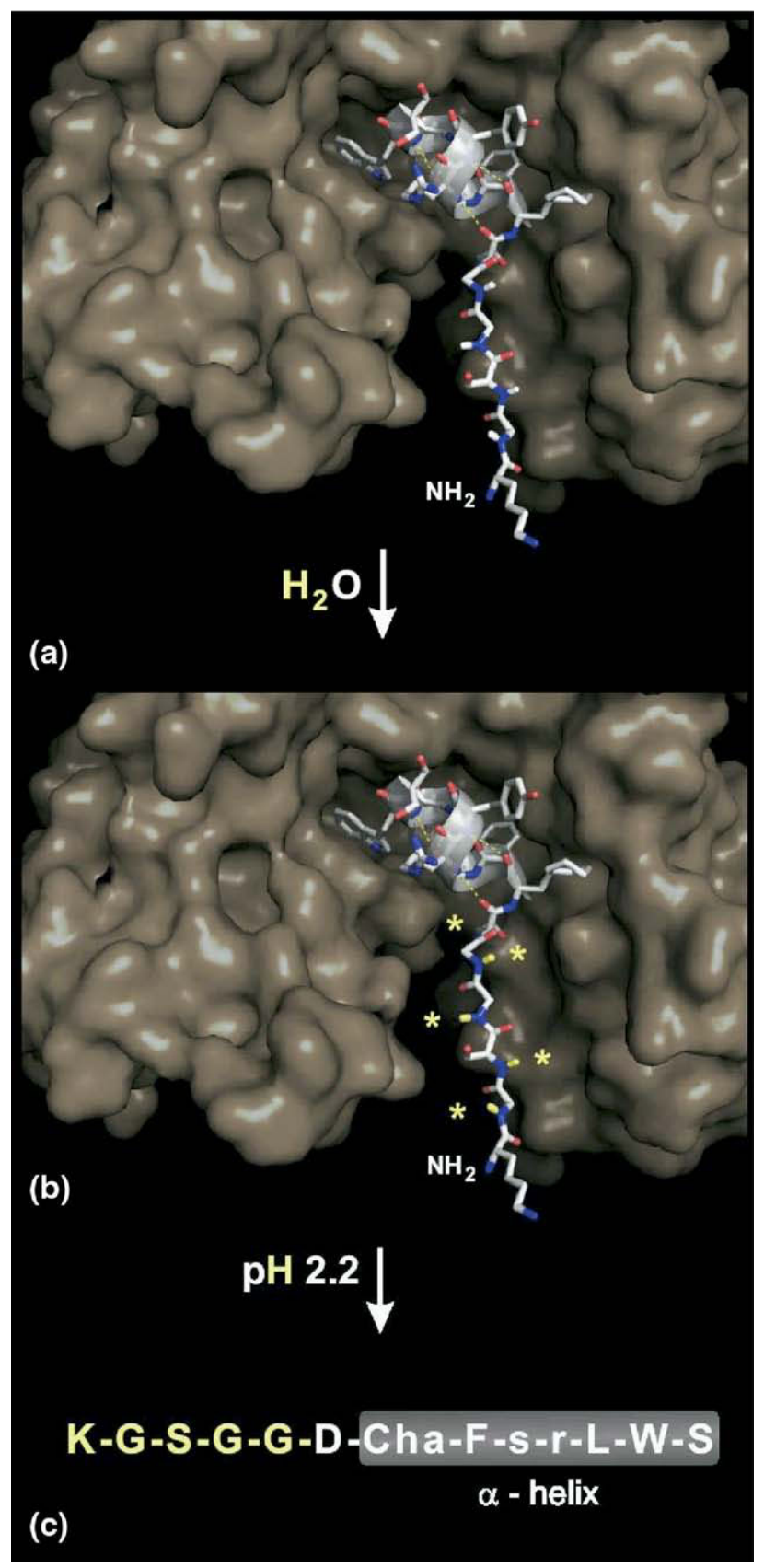

mingham, MA). The procedure for preparing microcolumns has been described previously [23]. To minimize deuterium loss during desalting and MALDI sample preparation, it was important to maintain low temperature and low $\mathrm{pH}$. A rack was designed to keep the tip of the microcolumn, which contains the reversed-phase material, submerged in ice-cold water during the entire desalting procedure. The sample solution $(10 \mu \mathrm{L})$ was mixed 1:1 (vol/vol) with ice-cold $0.1 \%$ trifluoroacetic acid (TFA) and loaded onto the microcolumn. The microcolumn was washed with $20 \mu \mathrm{L}$ ice-cold $0.1 \%$ TFA. The peptides were eluted from the column using $0.5 \mu \mathrm{L}$ ice-cold HCCA in $70 \%$ acetonitrile/0.1\% TFA (4 $\mathrm{mg} / \mathrm{mL}$ ) onto a cold MALDI plate, which was cooled by placing it on a cold $\left(-20^{\circ} \mathrm{C}\right)$ aluminum block. Subsequently, the MALDI plate was immediately loaded into the vacuum of the mass spectrometer and allowed to dry to completeness inside the first vacuum chamber $\left(1 \times 10^{-2}\right.$ millibar $)$.

\section{MALDI-TOF and TOF/TOF Mass Spectrometry}

Negative ion MALDI-TOF and MALDI-TOF/TOF mass spectra were acquired on an Applied Biosystems (Framingham, MA) 4700 Proteomics Analyzer equipped with a $200-\mathrm{Hz}$ neodymium:yttrium-aluminum-garnet laser operating at a wavelength of $355 \mathrm{~nm}$. A prototype version of this instrument has been described previously [24]. MALDI-TOF mass spectra were acquired in reflectron mode with 470 ns delayed extraction, accumulating 5000 laser shots; the acceleration voltage was $20 \mathrm{kV}$. For MS/MS experiments, the acceleration voltage was $8 \mathrm{kV}$, and the collision energy $\left(\mathrm{E}_{\mathrm{LAB}}\right)$ was $1 \mathrm{keV}$; 5000 laser shots were accumulated. Argon was used as

Figure 2. Regioselective deuterium labeling of peptide antagonist by protein stabilization of an $\alpha$-helix. The structural basis for the selective shielding of main chain amide hydrogen atoms located in the C-terminal half of the peptide AE133 (KGSGGDCha-FsrYLWS) when bound to UPAR is shown schematically in (a). This artistic representation is based on the structure of the AE147-uPAR complex solved by X-ray crystallography (see Figure 1) by modifying the peptide sequence to represent AE133. The shared core sequence forming the $\alpha$-helix is left unmodified (except for the D-Lys $\rightarrow$ D-Arg substitution) and the N-terminal extension (KGSGG), which is added arbitrarily and located in the solvent-exposed breach between uPAR domains I and III. In this experimental setting, the main chain amide groups of AE133 are deuterated in the complex as the peptide was incubated in ${ }^{2} \mathrm{H}_{2} \mathrm{O}$ before complex formation. Upon dilution into protiated solvent the exposed amide groups of AE133 undergo rapid isotopic exchange to incorporate protium [yellow sticks and asterisks in (b)], whereas the amide groups that are engaged in formation of the stable $\alpha$-helix remain deuterated for a significant time. This regioselective deuterium labeling is retained after acid induced complex dissociation and chromatographic purification due to an efficient quenching of the chemical exchange rates for the amide groups in the now unstructured and free peptide shown in (c). The schematic representations were created by PyMol (DeLano Scientific), using the PDB coordinates 1YWH [19] and modifying the peptide sequence manually. 
a collision gas at an indicated manifold pressure of $\sim 1 \times 10^{-6}$ millibar (note that the pressure is not measured directly in the CID collision chamber).

\section{Data Analysis}

The data analysis was carried out as described previously [6]. Briefly, the average deuterium content was determined by the difference in the average masses between nonlabeled ions and the corresponding deuterated ions. The average masses were determined from centroided isotopic distributions exported into a spreadsheet using nominal masses. To calculate the theoretical deuterium content for a fragment ion in case of $100 \%$ scrambling, the experimental deuterium content of the precursor ion was divided by the number of its exchangeable sites, and this ratio was then multiplied with the number of exchangeable sites in the fragment ion. It is generally observed for protonated peptides that the only exchangeable hydrogens are those attached to heteroatoms [4, 9]. For deprotonated peptides, however, some C-bonded hydrogens are also mobilized during the activation process [25-27]. The predominant backbone cleavage in the present study is an $\mathrm{N}-\mathrm{C}_{\alpha}$ cleavage at an Asp residue. The proposed mechanism for this cleavage involves deprotonation of the $C_{\beta}$ atom of Asp, thereby forming an enolate anion [26]. Accordingly, we have categorized the two $\mathrm{C}_{\beta^{-}}$ bonded hydrogens as being exchangeable. It should be noted, however, that this has only a minor effect on the theoretical deuterium levels for $100 \%$ scrambling. Thus, the theoretical value for the $\mathrm{N}$-terminal fragment, $\mathrm{C}_{5}-$ $\mathrm{CH}_{2} \mathrm{O}$, decreases by $\sim 7 \%$ when the $\mathrm{C}_{\beta}$-bonded hydrogens are categorized as labile.

\section{Results and Discussion}

The CID fragmentation pattern of AE133 (KGSGGDCha-FsrYLWS) in both positive and negative ion mode is dominated by site-selective cleavages at the central Asp $^{6}$ residue. The major fragmentation pathway of protonated AE133 is a cleavage of the $\mathrm{Asp}^{6}-\mathrm{Cha}^{7}$ amide bond yielding the complementary fragment ion pair $b_{6} / y_{8}$ (Figure 3a). Such a site-selective cleavage of an amide bond C-terminal to an Asp residue is known to occur when the number of protons is less than or equal to the number of basic residues (Arg) [28, 29]. Deprotonated AE133 fragments predominantly by a backbone cleavage of the $\mathrm{N}-\mathrm{C}_{\alpha}$ bond at $\mathrm{Asp}^{6}$ yielding the complementary fragment ion pair $c_{5} / z_{9}$ at $m / z 402.2$ and 1207.5 (theoretical values: $m / z 402.2$ and 1207.6) (Figure $3 \mathrm{~b})$. The $\mathrm{c}_{5}$ fragment undergoes further fragmentation and $\mathrm{CH}_{2} \mathrm{O}$ is lost from the side chain of Ser to give the abundant product ion $\mathrm{C}_{5}-\mathrm{CH}_{2} \mathrm{O}$ at $\mathrm{m} / \mathrm{z}$ 372.2. Similarly, the $\mathrm{z}_{9}$ ion dissociates further by elimination of $\mathrm{H}_{2} \mathrm{O}$ yielding the most abundant fragment ion $\mathrm{z}_{9}-\mathrm{H}_{2} \mathrm{O}$ at $\mathrm{m} / \mathrm{z}$ 1189.5. A subsequent loss of $\mathrm{CH}_{2} \mathrm{O}$ produces the fragment ion $\mathrm{z}_{9}-\mathrm{H}_{2} \mathrm{O}-\mathrm{CH}_{2} \mathrm{O}$ at $m / z$ 1159.5. The identity of the

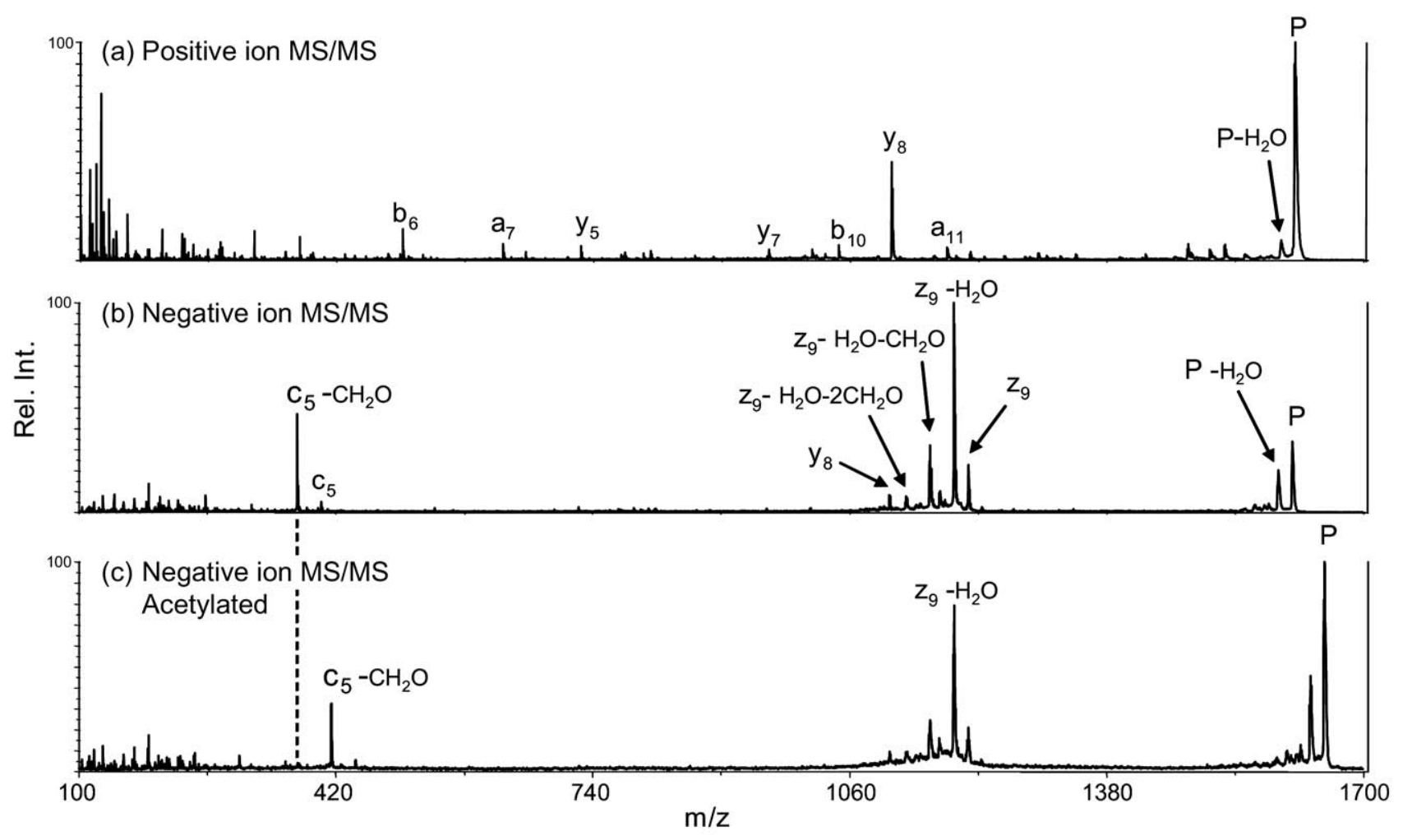

Figure 3. Collision-induced dissociation spectra of protonated and deprotonated AE133. (a) MALDITOF MS/MS of protonated AE133, (b) deprotonated AE133, and (c) deprotonated acetylated AE133. 
$\mathrm{C}_{5}-\mathrm{CH}_{2} \mathrm{O}$ and $\mathrm{z}_{9}-\mathrm{H}_{2} \mathrm{O}$ fragment ions were verified by negative ion mode CID of N-terminal acetylated AE133 (Figure $3 \mathrm{c}$ ). The results clearly show that $\mathrm{C}_{5}-\mathrm{CH}_{2} \mathrm{O}$ is a $\mathrm{N}$-terminal fragment and that $\mathrm{z}_{9}-\mathrm{H}_{2} \mathrm{O}$ is a C-terminal fragment. The pronounced loss of $\mathrm{H}_{2} \mathrm{O}$ from the $\mathrm{z}_{9}$ fragment as well as the $\mathrm{N}-\mathrm{C}_{\alpha}$ bond cleavage at $\mathrm{Asp}^{6}$ agree with the results of other investigators [30-32]. Similarly, the facile loss of $\mathrm{CH}_{2} \mathrm{O}$ from the side-chain of Ser in both $c_{5}$ and $z_{9}$ is in agreement with results obtained from dipeptides [33] and from larger peptides $[30,34]$.

The $\mathrm{c}_{5}-\mathrm{CH}_{2} \mathrm{O}$ fragment ion at $\mathrm{m} / \mathrm{z} 372.2$ constitutes a sensitive probe for the occurrence of amide hydrogen scrambling. Before ion activation the residues within this fragment contain $\sim 0$ deuterons as they belong to the nonbinding region of AE133. The onset of hydrogen scrambling is readily detected by the mass increase that inevitably results from migration of deuterium atoms from the C-terminal half of AE133 to the N-terminal half. Figure 4 shows the isotope distribution of the $\mathrm{C}_{5}-\mathrm{CH}_{2} \mathrm{O}$ fragment obtained from CID of deprotonated AE133 labeled with deuterium in the C-terminal half. It is clear from this spectrum that hydrogen scrambling has occurred as the isotopic envelope is mass shifted relative to the isotopic natural abundance distribution. The deuterium content of the $\mathrm{c}_{5}-\mathrm{CH}_{2} \mathrm{O}$ fragment (1.1) is close to the theoretical value for $100 \%$ scrambling (1.2). Similarly, the deuterium content of the most abundant C-terminal fragment $\mathrm{z}_{9}-\mathrm{H}_{2} \mathrm{O}(2.0)$ is in good agreement with the $100 \%$ scrambling value (1.8). Extensive positional randomization among all exchangeable hydrogens has thus occurred upon collisional activation of deprotonated AE133. A similar result was obtained for protonated AE133 [6, 7]. The occurrence of hydrogen scrambling for protonated peptides can be rationalized within the framework of the "mobile proton" model for peptide fragmentation [1, 35]. In this model, peptide bond dissociation is initiated by a proton transfer from a basic site to the less basic back-bone amide nitrogen. This endothermic reaction is facilitated by the vibrational excitation that results from collisional activation. The extensive scrambling is caused by reversible proton/deuteron transfer processes among all N- and O-bonded hydrogens in the activated peptide ion. An analogous situation exists in the deprotonated AE133 peptide, where a "mobile deprotonation site" (a term used in [17]) results in extensive hydrogen scrambling. The backbone amides are highly involved in the "mobile deprotonation" as evidenced by the intramolecular migration of amide deuterons from the C-terminal half of AE133 to its N-terminal residues. Interestingly, the deprotonation site may also include C-bonded hydrogens that are adjacent to a carbonyl group (thereby yielding an enolate ion). C-deprotonation has thus been shown to compete with deprotonation of a carboxyl group under kinetically controlled conditions, as acetic acid enolate $\left({ }^{-} \mathrm{CH}_{2} \mathrm{CO}_{2} \mathrm{H}\right)$ is formed together with acetate ion $\left(\mathrm{CH}_{3} \mathrm{CO}_{2}{ }^{-}\right)$when acetic acid reacts with $\mathrm{OH}^{-}$
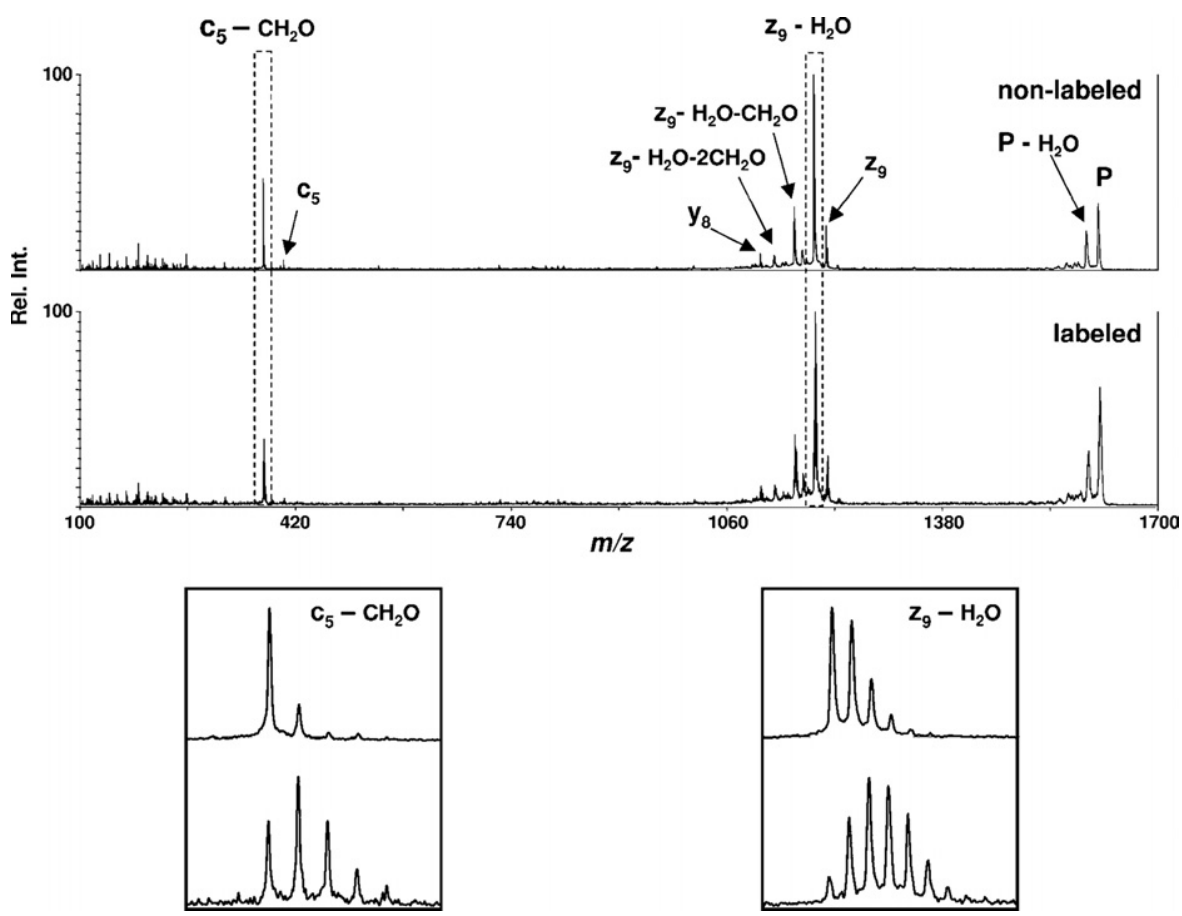

Figure 4. Hydrogen scrambling during gas-phase fragmentation of deprotonated selectively labeled AE133 peptide. MALDI-TOF MS/MS of the selectively labeled KGSGGD-Cha-FsrYLWS (AE133) and the nonlabeled control. The $\mathrm{C}_{5}-\mathrm{CH}_{2} \mathrm{O}$ is a sensitive probe for the occurrence of amide hydrogen scrambling because it contains $\sim 0$ deuterons before ion activation. The lower panel shows the isotopic distribution of the $\mathrm{C}_{5}-\mathrm{CH}_{2} \mathrm{O}$ and $\mathrm{z}_{9}-\mathrm{H}_{2} \mathrm{O}$ in the labeled (lower distribution) and nonlabeled (upper distribution) peptide. 
and other strong bases in the gas phase [36]. Also, low-energy CID experiments on smaller deprotonated peptides containing exclusively $\mathrm{H}$ or alkyl side chains have revealed a limited interchange between $\mathrm{C}$-bonded and N-bonded hydrogens during the formation of cions [25]. It is, however, not possible from our results to determine to what extent C-bonded hydrogens have participated in the scrambling processes. Nevertheless, our results show that the solution deuteration pattern of the deprotonated peptide is completely erased upon collisional activation. It is thus clear that backbone amides are highly involved in the deprotonation reactions in the activated peptide.

\section{Conclusions}

We have used a model peptide with a unique selective deuterium labeling to investigate the occurrence of gas-phase hydrogen scrambling upon collisional activation in negative ion mode. The deuterium content of the anionic N-terminal fragment ion, $\mathrm{C}_{5}-\mathrm{CH}_{2} \mathrm{O}$, reveals that amide deuterons from the $\mathrm{C}$-terminal half have migrated intramolecularly to the $\mathrm{N}$-terminal residues upon activation. These results clearly demonstrate that the backbone amides are highly "mobile deprotonation sites" in a vibrationally excited deprotonated peptide. Consequently, CID is not an adequate experimental tool for obtaining site-specific information about deuteration patterns of deprotonated peptides. Fragmentation by electron detachment dissociation (EDD) may, however, hold promise as a gas-phase fragmentation method for this particular purpose $[37,38]$. In EDD, the anionic peptide is irradiated with electrons and backbone dissociation occurs with limited vibrational excitation, as the fragment ions mostly retain their labile post translational modifications [38]. Thus, EDD may be used for deducing the solution deuteration pattern for deprotonated peptides, in a manner similar to electron capture dissociation (ECD) for protonated peptides [39]. Alternatively, MALDI in-source decay of deprotonated peptides is likely to preserve their solution deuteration pattern, as fragmentation by this technique occurs with a very low degree of scrambling for positive ions [40].

\section{Acknowledgments}

The authors acknowledge support for this work by grants from the Danish Biotech Research Academy (DBRA) sponsored by NovoZymes, The Danish Natural Science Research Council (FNU) (grant No. 272-06-0493), The Danish Instrument Biotechnology Center (DABIC), The Lundbeck Foundation, and The Carlsberg Foundation.

\section{References}

1. Paizs, B.; Suhai, S. Fragmentation Pathways of Protonated Peptides. Mass Spectrom. Rev. 2005, 24, 508-548.

2. Buijs, J.; Hagman, C.; Hakansson, K.; Richter, J. H.; Hakansson, P.; Oscarsson, S. Inter- and Intramolecular Migration of Peptide Amide Hydrogens During Electrospray Ionization. J. Am. Soc. Mass Spectrom. 2001, 12, 410-419.
3. Demmers, J. A. A.; Rijkers, D. T. S.; Haverkamp, J.; Killian, J. A.; Heck, A. J. R. Factors Affecting Gas-Phase Deuterium Scrambling in Peptide Ions and Their Implications for Protein Structure Determination. J. Am. Chem. Soc. 2002, 124, 11191-11198.

4. Harrison, A. G.; Yalcin, T. Proton Mobility in Protonated Amino Acids and Peptides. Int. J. Mass Spectrom. 1997, 165, 339-347.

5. Johnson, R. S.; Krylov, D.; Walsh, K. A. Proton Mobility Within Electrosprayed Peptide Ions. J. Mass Spectrom. 1995, 30, 386-387.

6. Jørgensen, T. J. D.; Bache, N.; Roepstorff, P.; Gårdsvoll, H.; Ploug, M. Collisional Activation by MALDI Tandem Time-of-Flight Mass Spectrometry Induces Intramolecular Migration of Amide Hydrogens in Protonated Peptides. Mol. Cell. Proteom. 2005, 4, 1910-1919.

7. Jørgensen, T. J. D.; Gårdsvoll, H.; Ploug, M.; Roepstorff, P. Intramolecular Migration of Amide Hydrogens in Protonated Peptides Upon Collisional Activation. J. Am. Chem. Soc. 2005, 127, 2785-2793.

8. McLafferty, F. W.; Guan, Z. Q.; Haupts, U.; Wood, T. D.; Kelleher, N. L. Gaseous Conformational Structures of Cytochrome c. J. Am. Chem. Soc. 1998, 120, 4732-4740.

9. Mueller, D. R.; Eckersley, M.; Richter, W. J. Hydrogen TransferReactions in the Formation of $Y+2$ Sequence Ions from Protonated Peptides. Org. Mass Spectrom. 1988, 23, 217-222.

10. Rand, K. D.; Jørgensen, T. J. D. Development of a Sensitive Peptide Probe for the Occurrence of Hydrogen $(1 \mathrm{H} / 2 \mathrm{H})$ Scrambling Upon Gas Phase Fragmentation. Anal. Chem. 2007, 79, 8686-8693.

11. Ferguson, P. L.; Pan, J. X.; Wilson, D. J.; Dempsey, B.; Lajoie, G.; Shilton, B.; Konermann, L. Hydrogen/Deuterium Scrambling During Quadrupole Time-of-Flight MS/MS Analysis of a Zinc-Binding Protein Domain. Anal. Chem. 2007, 79, 153-160.

12. Hoerner, J. K.; Xiao, H.; Dobo, A.; Kaltashov, I. A. Is There Hydrogen Scrambling in the Gas Phase? Energetic and Structural Determinants of Proton Mobility within Protein Ions. J. Am. Chem. Soc. 2004, 126, 7709-7717.

13. Deng, Y. Z.; Pan, H.; Smith, D. L. Selective Isotope Labeling Demonstrates That Hydrogen Exchange at Individual Peptide Amide Linkages Can be Determined by Collision-Induced Dissociation Mass Spectrometry. J. Am. Chem. Soc. 1999, 121, 1966-1967.

14. Kim, M. Y.; Maier, C. S.; Reed, D. J.; Deinzer, M. L. Site-Specific Amide Hydrogen/Deuterium Exchange in Escherichia coli Thioredoxins Measured by Electrospray Ionization Mass Spectrometry. J. Am. Chem. Soc. 2001, 123, 9860-9866.

15. Kim, M. Y.; Maier, C S.; Reed, D. J · Deinzer, M. L. Conformational Changes in Chemically Modified Escherichia coli Thioredoxin Monitored by H/D Exchange and Electrospray Ionization Mass Spectrometry. Protein Sci. 2002, 11, 1320-1329.

16. Kim, M. Y.; Maier, C. S.; Reed, D. J.; Ho, P. S.; Deinzer, M. L. Intramolecular Interactions in Chemically Modified Escherichia coli Thioredoxin Monitored by Hydrogen/Deuterium Exchange and Electrospray Ionization Mass Spectrometry. Biochemistry 2001, 40, 1441314421.

17. Clipston, N. L.; Jai-nhuknan, J.; Cassady, C. J. A Comparison of Negative and Positive Ion Time-of-Flight Post-Source Decay Mass Spectrometry for Peptides Containing Basic residues. Int. J. Mass Spectrom. 2003, 222, 363-381.

18. Jørgensen, T. J. D.; Gårdsvoll, H.; Danø, K.; Roepstorff, P.; Ploug, M. Dynamics of Urokinase Receptor Interaction with Peptide Antagonists Studied by Amide Hydrogen Exchange and Mass Spectrometry. Biochemistry 2004, 43, 15044-15057.

19. Llinas, P.; Le Du, M. H.; Gårdsvoll, H.; Danø, K.; Ploug, M.; Gilquin, B.; Stura, E. A.; Menez, A. Crystal Structure of the Human Urokinase Plasminogen Activator Receptor Bound to an Antagonist Peptide. EMBO J. 2005, 24, 1655-1663.

20. Ploug, M.; Østergaard, S.; Gårdsvoll, H.; Kovalski, K.; Holst-Hansen, C.; Holm, A.; Ossowski, L.; Danø, K. Peptide-Derived Antagonists of the Urokinase Receptor Affinity Maturation by Combinatorial Chemistry, Identification of Functional Epitopes, and Inhibitory Effect on Cancer Cell Intravasation. Biochemistry 2001, 40, 12157-12168.

21. Ploug, M.; Østergaard, S.; Hansen, L. B.; Holm, A.; Danø, K. Photoaffinity Labeling of the Human Receptor for Urokinase-Type Plasminogen Activator Using a Decapeptide Antagonist. Evidence for a Composite Ligand-Binding Site and a Short Interdomain Separation. Biochemistry 1998, 37, 3612-3622.

22. Ploug, M.; Kjalke, M.; Rønne, E.; Weidle, U.; Høyer-Hansen, G.; Danø, K. Localization of the Disulfide Bonds in the NH2-Terminal Domain of the Cellular Receptor for Human Urokinase-Type Plasminogen Activator. A Domain Structure Belonging to a Novel Superfamily of Glycolipid-Anchored Membrane Proteins. J. Biol. Chem. 1993, 268, 17539-17546.

23. Gobom, J.; Nordhoff, E.; Mirgorodskaya, E.; Ekman, R.; Roepstorff, P. Sample Purification and Preparation Technique Based on Nano-Scale Reversed-Phase Columns for the Sensitive Analysis of Complex Peptide Mixtures by Matrix-Assisted Laser Desorption/Ionization Mass Spectrometry. 1999, 34, 105-116.

24. Medzihradszky, K. F.; Campbell, J. M.; Baldwin, M. A.; Falick, A. M. Juhasz, P.; Vestal, M. L.; Burlingame, A. L. The Characteristics of Peptide Collision-Induced Dissociation Using a High-Performance MALDI-TOF/TOF Tandem Mass Spectrometer. Anal. Chem. 2000, 72 552-558.

25. Harrison, A. G. Sequence-Specific Fragmentation of Deprotonated Peptides Containing H or Alkyl Side Chains. J. Am. Soc. Mass Spectrom. 2001, $12,1-13$. 
26. Bowie, J. H.; Brinkworth, C. S.; Dua, S. Collision-Induced Fragmentations of the $(\mathrm{M}-\mathrm{H})(-)$ Parent Anions of Underivatized Peptides: An Aid to Structure Determination and Some Unusual Negative Ion Cleavages. Mass Spectrom. Rev. 2002, 21, 87-107.

27. Harrison, A. G. Characterization of $\alpha$ - and $\gamma$-Glutamyl Dipeptides by Negative Ion Collision-Induced Dissociation. J. Mass Spectrom. 2004, 39, $136-144$.

28. Tsaprailis, G.; Nair, H.; Somogyi, A.; Wysocki, V. H.; Zhong, W. Q.; Futrell, J. H.; Summerfield, S. G.; Gaskell, S. J. Influence of Secondary Structure on the Fragmentation of Protonated Peptides. J. Am. Chem. Soc. 1999, 121, 5142-5154.

29. Tsaprailis, G.; Somogyi, A.; Nikolaev, E. N.; Wysocki, V. H. Refining the Model for Selective Cleavage at Acidic Residues in Arginine-Containing Protonated Peptides. Int. J. Mass Spectrom. 2000, 196, 467-479.

30. Steinborner, S. T.; Bowie, J. H. The Negative Ion Mass Spectra of M $\mathrm{H}(-)$ ions derived from Caeridin and Dynastin Peptides. Internal Backbone Cleavages Directed Through Asp and Asn Residues. Rapid Commun. Mass Spectrom. 1997, 11, 253-258.

31. Brinkworth, C. S.; Dua, S.; McAnoy, A. M.; Bowie, J. H. Negative Ion Fragmentations of Deprotonated Peptides: Backbone Cleavages Directed Through both Asp and Glu. Rapid Commun. Mass Spectrom. 2001, 15, 1965-1973.

32. Harrison, A. G.; Young, A. B. Fragmentation Reactions of Deprotonated Peptides Containing Aspartic Acid. Int. J. Mass Spectrom. 2006, 255, $111-122$.

33. Waugh, R. J.; Eckersley, M.; Bowie, J. H.; Hayes, R. N. CollisionInduced Dissociations of Deprotonated Peptides -Dipeptides Con- taining Serine or Threonine. Int. J. Mass Spectrom. Ion Processes 1990, 98, 135-145.

34. Reiter, A.; Teesch, L. M.; Zhao, H.; Adams, J. Gas-Phase Fragmentations of Anionic Complexes of Serine-Containing and Threonine-Containing Peptides. Int. J. Mass Spectrom. Ion Processes 1993, 127, 17-26.

35. Dongre, A. R.; Jones, J. L.; Somogyi, A.; Wysocki, V. H. Influence of Peptide Composition, Gas-Phase Basicity, and Chemical Modification on Fragmentation Efficiency: Evidence for the Mobile Proton Model. J. Am. Chem. Soc. 1996, 118, 8365-8374.

36. Grabowski, J. J.; Cheng, X. H. Gas-Phase Formation of the Enolate Monoanion of Acetic Acid by Proton Abstraction. J. Am. Chem. Soc. 1989, 111, 3106-3108

37. Kjeldsen, F.; Silivra, O. A.; Ivonin, I. A.; Haselmann, K. F.; Gorshkov, M. Zubarev, R. A.C- $\alpha$-C Backbone Fragmentation Dominates in Electron Detachment Dissociation of Gas-Phase Polypeptide Polyanions. Chem. Eur. J. 2005, 11, 1803-1812.

38. Budnik, B. A.; Haselmann, K. F.; Zubarev, R. A. Electron Detachmen Dissociation of Peptide Dianions: An Electron-Hole Recombination Phenomenon. Chem. Phys. Lett. 2001, 342, 299-302.

39. Rand, K. D.; Adams, C. M.; Zubarev, R. A.; Jørgensen, T. J. D. Electron Capture Dissociation Proceeds with a Low Degree of Intramolecular Migration of Peptide Amide Hydrogens. J. Am. Chem. Soc. 2008, 130, 1341-1349.

40. Bache, N.; Rand, K. D.; Roepstorff, P.; Jørgensen, T. J. D. Gas-Phase Fragmentation of Peptides by MALDI in-Source Decay with Limited Amide Hydrogen $(1 \mathrm{H} / 2 \mathrm{H})$ Scrambling. Anal. Chem., in press. 